\title{
Isotopic fractionation of sulfur in micro zones of tidal flat sediments
}

\author{
Toshiro Yamanaka, Tatsushi Murae and Hitoshi Chiba \\ Department of Earth and Planetary Sciences, Faculty of Science, Kyushu University, \\ Hakozaki, Fukuoka 812-8581, Japan
}

(Received April 25, 1997; Accepted October 29, 1998)

\begin{abstract}
Sulfur cycles in micro zones of sediments at a tidal flat was investigated using isotope fractionation $\left(\delta^{34} \mathrm{~S}\right)$ of sulfate, acid volatile sulfides (AVS), and pyrite. Aerobic oxidation is major driving force for the sulfur cycle in the sediments that located very close to the sediment surface $(0.5 \mathrm{~mm}$ depth from the sediment surface) in the tidal flat. During this cycle isotopically light sulfate is accumulated. Shift of $\delta^{34} \mathrm{~S}$ values of the sulfate toward positive direction proceeds with reduction by sulfur reduction bacteria (SRB) under anoxic conditions at depths between $0.5 \mathrm{~cm}$ and $7 \mathrm{~cm}$ below the sediment surface. At the depth where the shells locate $\left(15 \mathrm{~cm}\right.$ below the sediment surface), the major sulfur compound is pyrite. The $\delta^{34} \mathrm{~S}$ values of the AVS are between those of sulfate and pyrite for sediment samples collected at both inside and outside the shells. Although sulfate $\delta^{34} \mathrm{~S}$ and pyrite $\delta^{34} \mathrm{~S}$ values are almost the same for the inside and outside of the shells, the difference of the AVS $\delta^{34}$ S values between the inside and outside is quite significant. Seasonal variation of $\delta^{34} \mathrm{~S}$ values was also observed for the AVS. Unknown sulfur oxidizing bacteria (SB), which oxidize AVS into sulfate accompanying significant sulfur isotope fractionation under anoxic conditions, may play the major role of the isotope fractionation.
\end{abstract}

\section{INTRODUCTION}

Sulfur is an important redox element under natural aquatic conditions, and it is responsible for a number of important biogeochemical processes, such as sulfate reduction (Lord and Church, 1983), pyrite formation (Howarth, 1979), metal cycling (Boulegue et al., 1982), and salt-marsh ecosystem energetics (Howarth, 1984). Therefore, the biogeochemical role of sulfur in tidal wetlands is an area of intense research (Luther et al., 1986).

Four principal components in sedimental sulfur cycles are hydrogen sulfide $\left(\mathrm{H}_{2} \mathrm{~S}\right)$, acid volatile sulfur (AVS), elemental sulfur $\left(\mathrm{S}^{0}\right)$ and pyrite (Berner, 1984). $\mathrm{H}_{2} \mathrm{~S}$ is yielded by bacterial reduction of sulfate under anoxic. conditions using organic matter as a reductant. AVS (a series of metastable iron monosulfides such as $\mathrm{FeS}$ ) is formed on reactions of the $\mathrm{H}_{2} \mathrm{~S}$ with detrital iron. $\mathrm{S}^{0}$ is formed by bacterial oxidation of $\mathrm{H}_{2} \mathrm{~S}$. Reaction of the $\mathrm{FeS}$ with the $\mathrm{S}^{0}$ gives pyrite. Sulfatereducing bacteria (SRB) and sulfur bacteria (SB) principally contribute the redox transformations of sulfur compounds in sediments. These bacteria use the energy obtained on the redox reactions for syntheses and degradations of organic compounds in their metabolic pathways (Summons, 1993). It is well known that many of the SRB exhibit pronounced isotopic fractionation of sulfur during their metabolisms, especially, on reduction of sulfates (Kaplan and Rittenberg, 1964).

The isotopic fractionation of sulfur has been used as one of valuable evaluation methods of sedimentary environments. Kajiwara (1989) used $\delta^{34} \mathrm{~S}$ values of sulfur compounds in sediments as indicators for redox states of water overlying the sediments. Ohmoto and Felder (1987) estimated temperature of ancient water and bacterial activity on the bases of sulfur isotopic fractionation in sediments. The $\delta^{34} \mathrm{~S}$ values in these studies have been determined for samples that represent the average of the sedimentary environments. Novitsky and coworkers (1981), however, have revealed that the downward transition from aerobic to anaerobic conditions in a harbor mud is not simply a function of the biological consumption of oxygen, and 
that the sedimentary environments are constructed with several different micro zones. Therefore, it is necessary to examine bacterial activities and sulfur isotopic fractionations in each micro zone in order to understand details of sedimentary environments. In this investigation, we examined sulfur isotope fractionation in micro sedimentary zones differentiated by dead-bivalve shells in a tidal flat.

\section{SAMPLES}

The sediments samples were collected inside and outside of shells of dead bivalves, Cyclina sinensis, at a tidal flat in a small inlet (open to the Sea of Japan) locating at Tsuyazaki, Fukuoka, Japan $\left(33^{\circ} 47^{\prime} \mathrm{N}, 130^{\circ} 28^{\prime}\right.$ E) during May '93 and June ' 95 (Fig. 1). The shells located approximately $15 \mathrm{~cm}$ below the sediment surface. The burying depth and standing angle of the shells in mud was similar to that of living one to indicate no occurrence of sedimentary rework around it. The mouth of the shell was open slightly. The black color of the shell surface showed preservation of conchiolin, suggesting the shellfish death within past few years. We collected more than 5 shell samples on each sampling at the same sampling point. The average weight of the shells containing sediments inside was about $30 \mathrm{~g}$. Oxidation potential (Eh: $\mathrm{mV}$ ) of the samples were determined immediately after the collection. Column samples of sediment between $0 \mathrm{~cm}$ and $12 \mathrm{~cm}$ below sediment surface were collected in order to examine the surroundings of the shell. The seawater samples were collected at the surface of the sediment samples at low tide. All samples were cooled with ice immediately after the collection, and kept at the temperature until the beginning of analyses of sulfur contents.

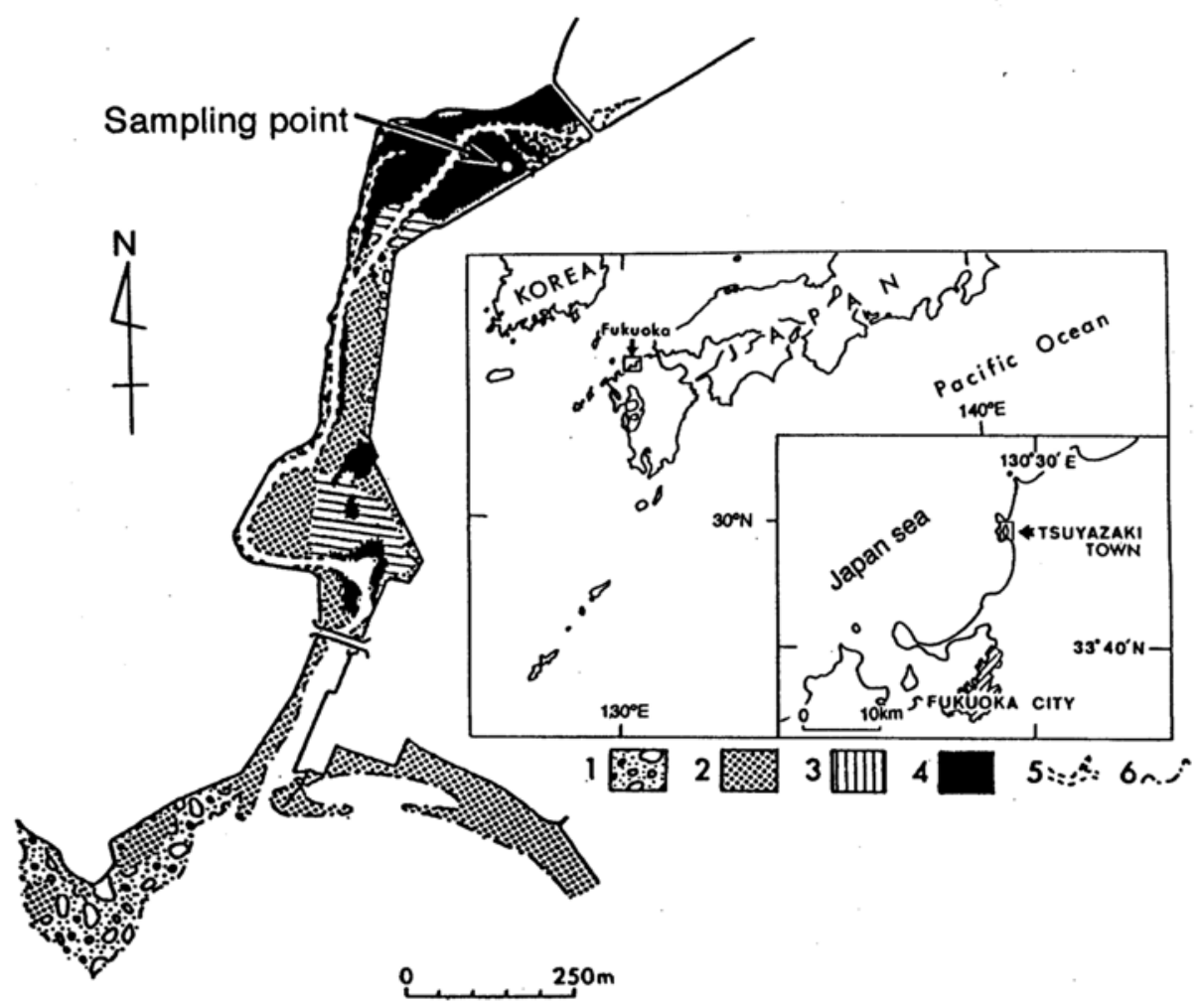

Fig. 1. Sampling point and distribution of bottom sediments in the Tsuyazaki inlet: $1=$ gravel and rock; $2=$ sand-flat; 3 = muddy sand-flat; 4 = mud-flat; $5=$ main tidal channel; $6=$ mean low-water springs. 


\section{Analytical Methods}

\section{Sulfur content}

Sulfate: We used barium sulfate gravimetry methods developed by Kolthoff et al. (1969) in order to determine the content of sulfate in the sediment samples. Hydrochloric acid and distilled water were added to the sediment samples in the sampling day in order to avoid the alteration of $\delta^{34} \mathrm{~S}$ values of sulfate and AVS by air oxidation. The resultant $\mathrm{H}_{2} \mathrm{~S}$ gas in the samples was removed by bubbling of $\mathrm{N}_{2}$. After removal of the AVS, clastic matters in the remaining suspended samples were removed by filtration. The filtrate was heated to near the boiling point and sulfate anion was precipitated as barium sulfate on addition of $5 \%$ $\mathrm{BaCl}_{2}$ aqueous solution. By the similar way, sulfate anion in the seawater samples, which were filtered through a membrane filter $(0.45 \mu \mathrm{m})$, was isolated as precipitates of barium sulfate. These barium sulfates were washed with hot distilled water several times, dried at $110^{\circ} \mathrm{C}$, and kept in a desiccator until analysis. The weight of $\mathrm{BaSO}_{4}$ was determined by the conventional burning methods.

AVS: The content of total acid volatile sulfur (AVS) such as $\mathrm{FeS}$ and $\mathrm{H}_{2} \mathrm{~S}$ in the sediment samples was determined following the methods described by Tsutsumi et al. (1991). AVS in the sediment was extracted as $\mathrm{H}_{2} \mathrm{~S}$ by addition of hydrochloric acid into the sample immediately after bringing back to the laboratory. The evolved $\mathrm{H}_{2} \mathrm{~S}$ was introduced into saturated cadmium acetate aqueous solution (adjusted to $\mathrm{pH} 9-10$ with sodium hydroxide) with nitrogen stream to give precipitates of cadmium sulfide. The precipitates were separated using a glass fiber filter and then put in a mixed solution of nitric acid and bromine to oxidize the cadmium sulfide into sulfate. The reaction mixture was heated in a water bath to remove excess nitric acid and bromine. Then distilled water and conc. hydrochloric acid was added into the solution. After filtration, the sulfate anion yielded on the oxidation was precipitated as barium sulfate.

Pyrite: We determined the pyrite content in the sediment samples following the methods de- scribed by Ohtsubo (1995). The sediment samples, which were kept in a freezer until treatments, were washed several times with distilled water to remove sulfate. Then, high-density clastic fraction containing pyrite was separated by the dense media separation technique using bromoform $(d=$ 2.9). The high-density fraction was oxidized with mixture of nitric acid and bromine. The resultant sulfate ion was isolated as barium sulfate following the same methods as mentioned above. Each sulfur content was reported as $\mathrm{mg} \mathrm{S}$ in $1 \mathrm{~g}$ of dry sediment.

Elemental sulfur: We separated elemental sulfur in the sediment samples in the day of sampling in order to prevent oxidation by sulfur-oxidizing bacteria. After removal of AVS by addition of acid, the remaining sample was washed with distilled water to remove sulfate, and then dried. Elemental sulfur in the dried sample was extracted with diethyl ether for 3 hours using a Soxhlet extractor. The extracted elemental sulfur was converted into sulfate by oxidation with aqua regia, and the sulfate was precipitated as barium sulfate.

\section{Sulfur isotope ratio}

Sulfur isotope ratios of sulfate, AVS, elemental sulfur, and pyrite were measured individually. The barium sulfate prepared from the sulfate, AVS, pyrite, and elemental sulfur in the sediment samples as mentioned above was used for isotope analysis. The barium sulfate was converted to $\mathrm{SO}_{2}$ following the method of Yanagisawa and Sakai (1983). The $\delta^{34} \mathrm{~S}$ values were determined using a double inlet mass spectrometer (VG Isogas, SIRA10) at Institute for Study of the Earth's Interior, Okayama University.

\section{The number of bacteria}

The number of SRB and aerobe in the sediment samples was determined by the Most-ProbableNumber (MPN) method described by Alexander (1965). The medium for cultivation of SRB contained bacto peptone $(5 \mathrm{~g} / \mathrm{l})$, bacto yeast extract $(1 \mathrm{~g} / \mathrm{l}), \mathrm{FePO}_{3}(0.1 \mathrm{~g} / \mathrm{l})$, seawater (1-1), $\mathrm{pH} 7.5$. The cultivation medium for aerobes was prepared just before the use by combining sterilized medium $\mathrm{A}$ 
(sodium lactate: $3.5 \mathrm{~g} / \mathrm{l}, \mathrm{NH}_{4} \mathrm{Cl}: 1 \mathrm{~g} / \mathrm{l}, \mathrm{K}_{2} \mathrm{HPO}_{4}: 0.5$ $\mathrm{g} / \mathrm{l}, \mathrm{CaCl}_{2} \cdot 2 \mathrm{H}_{2} \mathrm{O}: 0.1 \mathrm{~g} / \mathrm{l}, \mathrm{MgSO}_{4} \cdot 7 \mathrm{H}_{2} \mathrm{O}: 2 \mathrm{~g} / \mathrm{l}$, east extract: $1 \mathrm{~g} / \mathrm{l}, \mathrm{FeSO}_{4}\left(\mathrm{NH}_{4}\right) \mathrm{SO}_{4} \cdot 6 \mathrm{H}_{2} \mathrm{O}: 0.5 \mathrm{~g} / \mathrm{l}$, resazurin: $0.01 \mathrm{mg} / \mathrm{l}$, seawater $1-1)$, sterilized medium B (sodium ascorbate: $0.5 \mathrm{~g} / 50 \mathrm{ml}, \mathrm{pH} 7.5$ ), and sterilized medium $\mathrm{C}$ (sodium thioglycolate: $0.5 \mathrm{~g} / 50 \mathrm{ml}, \mathrm{pH} 7.5)$. The $\mathrm{pH}$ was maintained at 7.5 by addition of $0.1 \mathrm{~N} \mathrm{KOH}$. The ABS was cultivated at $28^{\circ} \mathrm{C}$ for 2 weeks, and the aerobes at $25^{\circ} \mathrm{C}$ for 3 weeks.

The cultivation was carried out using 5 tubes containing samples diluted by 10 times each tube. The decision of growth of the bacteria was done on the basis of optical dispersion and of formation of black precipitation of $\mathrm{FeS}$. We calculated the MPN based on the table of the Society of Soil Microbiology Japan (Ishikuri, 1992).

\section{RESULTS}

\section{Redox potential and bacterial activity}

The sulfur cycle in salt marsh such as tidal flat starts by bacterial reduction of seawater sulfate (Luther et al., 1986). Redox conditions of the sediments seriously affect the growth of sulfur reducing bacteria (SRB). Redox potential (Eh) was measured for the sediment samples inside and outside of the shells at different seasons (Fig. 2). Figure 2 indicates that $\mathrm{Eh}$ at warm season is low compare to cool season. The Eh value inside the shells was much lower than that outside. The best growth conditions for usual SRB are reported to be lower than $-150 \mathrm{mV}$ (Postgate, 1984). Therefore, the activity of SRB is supposed to be high in the inside sediments at warm seasons. The number of SRB (Fig. 3) confirms this expectation.

\section{Content of sulfur compounds}

We could not determine the amount of organic sulfur because of technical difficulty, though the importance of the emission of organic sulfur compounds from tidal wetlands has been suggested. The amount of free sulfur was too low to isolate for quantitative analysis. Therefore, we examined the content of only three types of sulfur compounds (sulfate, AVS, and pyrite).

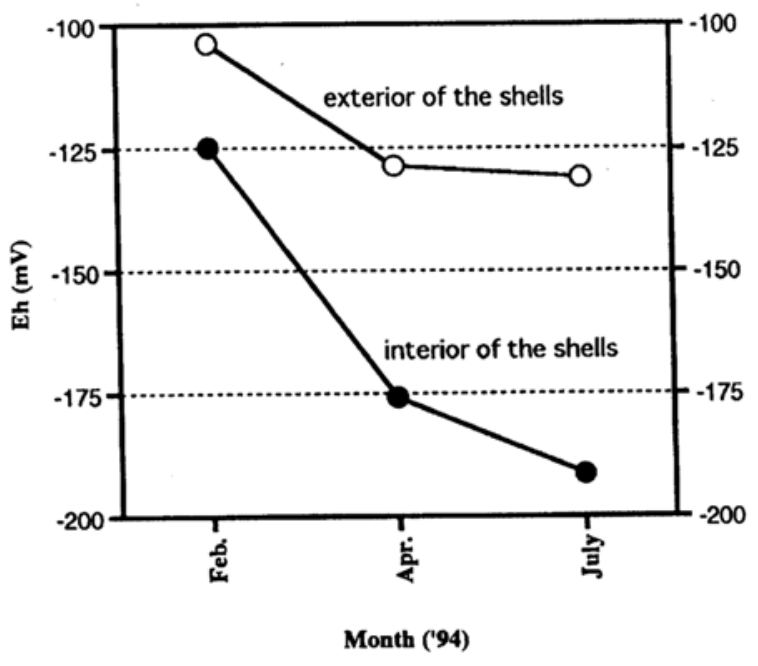

Fig. 2. Redox potential (Eh value: $m V$ ) in the sediment inside (-) and outside (-O-) of shell.

Seasonal variation of the average of the content of each type of sulfur compounds is plotted in Fig. 4. Pyrite is the major sulfur compound in the sediment samples through all seasons. The contents of sulfate and AVS are much lower than that of pyrite. The amount of sulfate tends to slightly exceed that of AVS. The feature of seasonal variation of the contents of these sulfur compounds is different between inside and outside of the shells. The content of each sulfur compound tends to be higher for the inside of the shell than the surroundings. Although Berner (1984) has suggested that the amount of pyrite in sediments correlates to the activity of SRB, the feature of seasonal variation of the pyrite content of the sediments inside the shells does not correlate with the SRB activity.

\section{Sulfur isotopes}

The $\delta^{34} \mathrm{~S}$ values of the three types of sulfur compounds in the sediments are shown in Table 1. Among those compounds, sulfate is isotopically the heaviest component and pyrite is the lightest one. The average of $\delta^{34} \mathrm{~S}$ of sulfate in the seawater at the sediment surface $(20.42 \%$ o $)$ is slightly heavier than that of sulfate $(19.55 \%)$ in the sediments just outside the shells. The average $\delta^{34} \mathrm{~S}$ of 


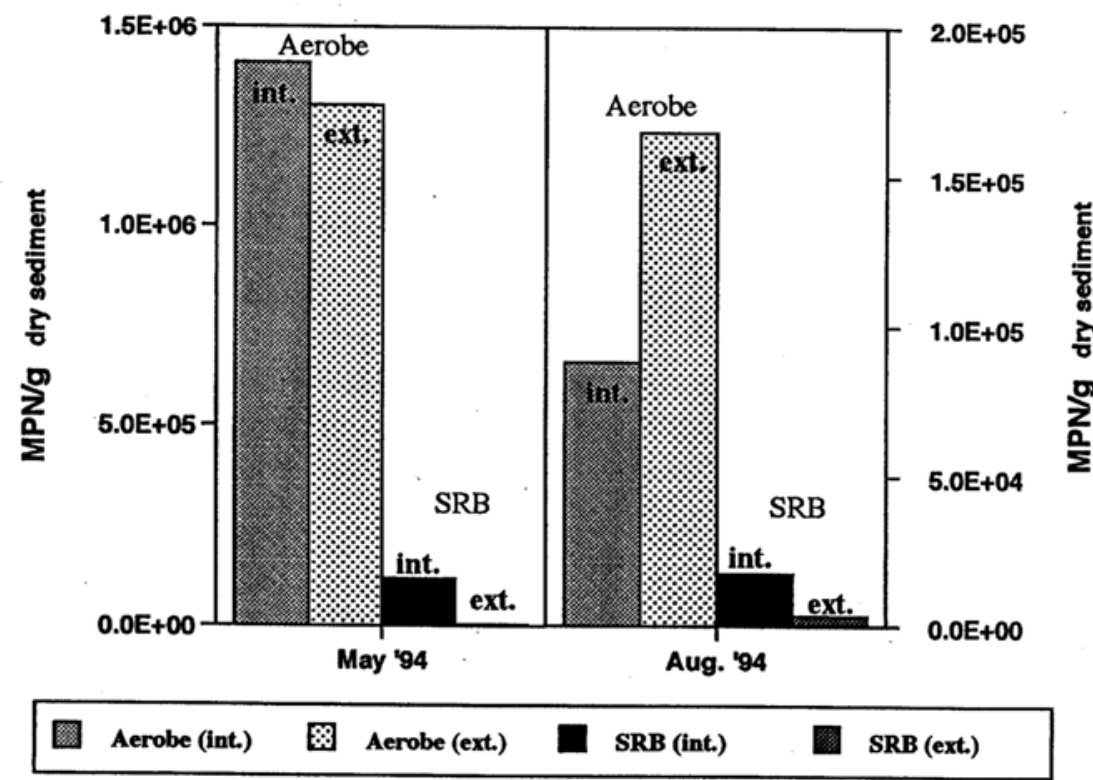

Fig. 3. Number of sulfur reducing bacteria $(S R B)$ and aerobe in the tidal flat sediments.

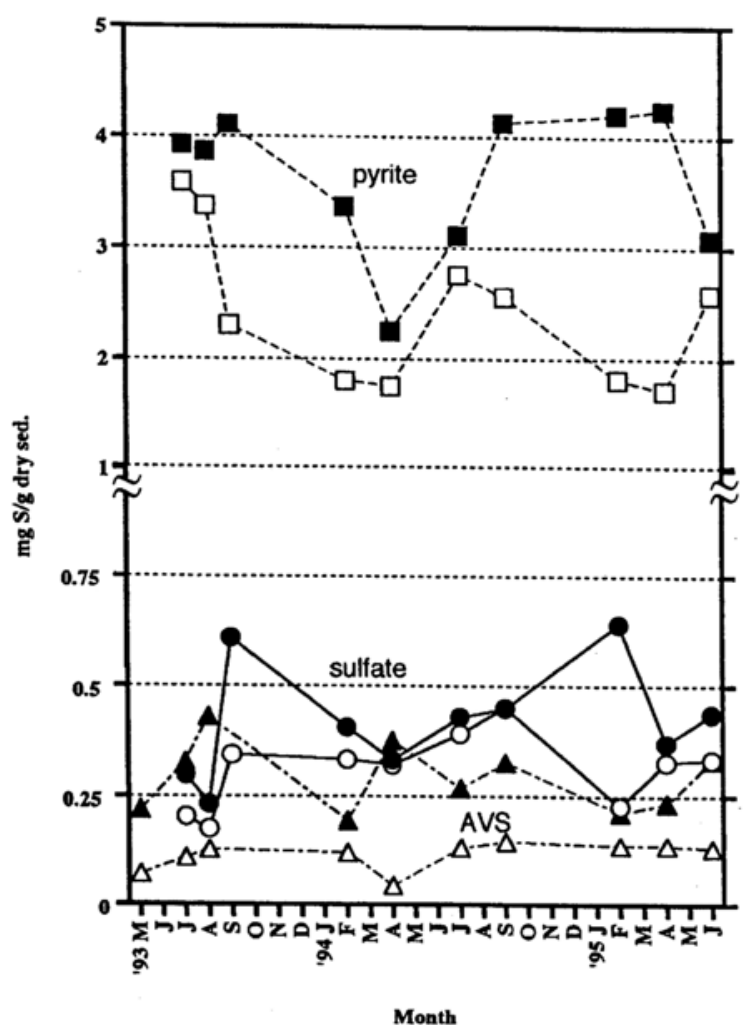

Fig. 4. Seasonal variation of amounts of sulfur compounds in the tidal flat sediments. O: Sulfate (exterior), $\bullet$ : Sulfate (interior), $\triangle:$ AVS (exterior), $\Delta$ : AVS (interior), $\square$ : Pyrite (exterior), $\mathbf{\square}$ : Pyrite (interior).

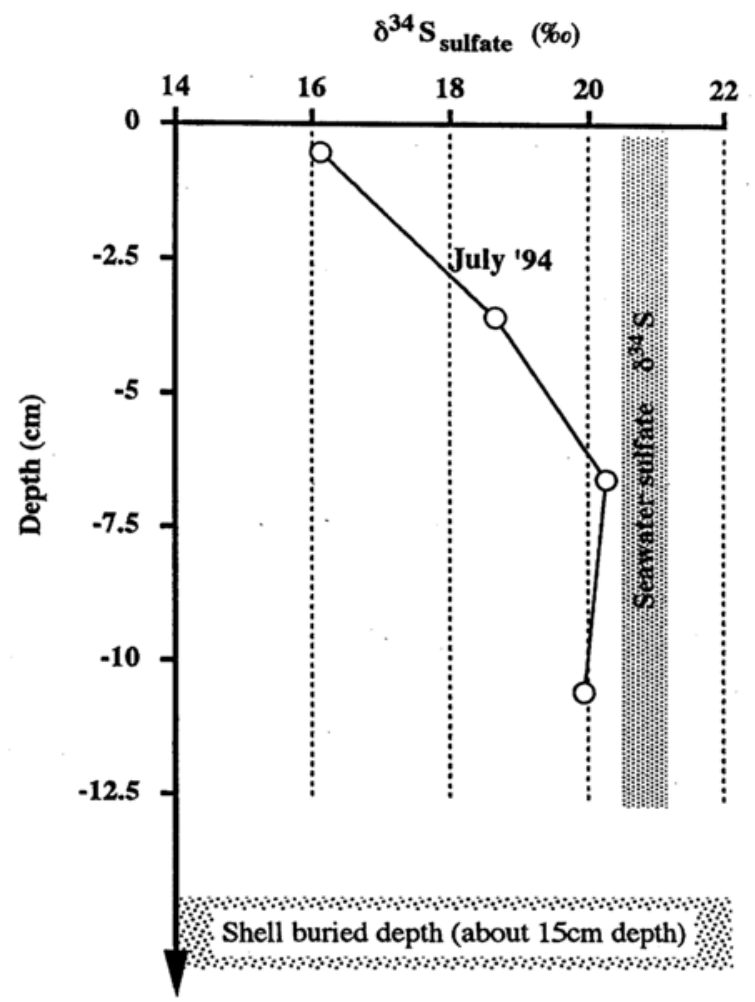

Fig. 5. Profile of $\delta^{34} S$ of pore-water sulfate along sampling depth from sediment surface. 
Table 1. Sulfur isotope fractionation of sulfur compounds in the sediments outside and inside dead bivalve shells at the tidal flat (the values show $\delta^{34} S_{C D T}(\% \circ)$ )

\begin{tabular}{lccccccc}
\hline & Sep.'93 & Apr. '94 & Sep. '94 & Feb. '95 & Apr. '95 & Jun. '95 & Average \\
\hline Sulfate-Inside & n.d. & n.d. & 20.56 & 19.61 & 20.78 & 18.97 & 19.98 \\
Sulfate-Outside & n.d. & n.d. & 19.53 & 18.82 & 19.55 & 20.33 & 19.55 \\
AVS-Inside & -8.12 & -2.59 & -15.20 & -14.27 & -11.67 & -10.88 & -10.45 \\
AVS-Outside & -19.68 & -22.29 & -20.63 & -23.13 & -21.13 & -18.52 & -20.90 \\
Pyrite-Inside & -26.08 & n.d. & n.d. & -25.75 & -25.20 & -25.06 & -25.52 \\
Pyrite-Outside & -24.07 & n.d. & n.d. & -25.92 & -26.07 & -25.99 & -25.51 \\
\hline
\end{tabular}

Elemental S* Oct. '94

$-22.22$

$-22.22$

\begin{tabular}{ccccccc}
\hline Seawater sulfate** & S1 & S2 & S3 & S4 & S5 & \\
\hline & 20.71 & 18.93 & 20.85 & 20.96 & 20.66 & 20.416 \\
\hline
\end{tabular}

n.d.: Not determined.

*Determined only for one sample collected outside.

**Determined for seawater collected at different sample points (SI-S5).

pyrite in the inside sediments is $-25.52 \%$. The $\delta^{34} \mathrm{~S}$ of elemental sulfur $(-22.22 \%$ o), which was measured only for one sample (external sediment) because of too low content in other samples, is intermediate between those of the external AVS and the external pyrite (Table 1).

Although pronounced difference was not observed for pyrite $\delta^{34} \mathrm{~S}$ and sulfate $\delta^{34} \mathrm{~S}$ between the outside and the inside of the shells, the average $\delta^{34} \mathrm{~S}$ of AVS showed significant difference between the inside $(-10.45 \%$ ) and the outside $(-20.90 \%$ o). Remarkable seasonal variation of AVS $\delta^{34} \mathrm{~S}$ is observed inside the shells.

Figure 5 shows alteration of sulfate ion according to the depth in the column of the sediment outside the shells. The sulfate in the seawater collected at the surface of the sediment samples showed almost the same $\delta^{34} \mathrm{~S}$ value as the mean value of ocean water sulfate reported by Rees (1973). The sulfate $\delta^{34} \mathrm{~S}$ in the sediment column does not exceed that of the seawater sulfate.

\section{Discussion}

Recycling of sulfur compounds: No increasing deposition of sulfur compounds with time as shown in Fig. 4 indicates recycling of these compounds in the sediments. Revsbech and coworkers (1980) have revealed the presence of the maximum oxygen content at about $2 \mathrm{~mm}$ below the surface in tidal sediments. Bacterial photosynthesis causes the increment of oxygen. The free oxygen oxidizes the AVS, which was produced by reduction of pore-water sulfate with SRB, into sulfate (Pooley, 1982). Therefore, the sulfate in pore water is recycled until all of the free oxygen being consumed between the depth of $5 \mathrm{~mm}$ and $7 \mathrm{~mm}$ below the surface of the sediments (Revsbech et al., 1980). Isotopically light sulfate at a depth close to sediment surface (ca. $5 \mathrm{~mm}$ below surface) in Fig. 5 is probably produced by the recycling because no isotope fractionation is supposed during the freeoxygen oxidation (Hallberg, 1985).

Contribution of the recycling system by freeoxygen oxidation may decrease with increase of the depth because of the depletion of molecular oxygen. However, recycling of AVS and pyrite into sulfate ion continues with bacterial oxidation under anoxic conditions (Aller and Rude, 1988). Supply of seawater sulfate decreases with increase of the depth. Therefore, the concentration of isotopically heavy sulfate remaining after isotope 
fractionation by SRB increases with depth up to the zone where the fractionation is equilibrated. In our case (Fig. 5), all of the sulfur compounds may have been fully recycled at $7.5 \mathrm{~cm}$ below the sediment surface.

Isotope fractionation of sulfate and pyrite: Seasonal variations of the isotope fractionation of the sulfur compounds are shown in Fig. 6. The $\delta^{34} \mathrm{~S}$ values of the sulfate and pyrite do not show recognizable seasonal variation. And both of the sulfate and pyrite exhibit negligibly small differences of $\delta^{34} \mathrm{~S}$ between inside and outside of the shells. This fact can be interpreted with full recycling of sulfur compounds (Kajiwara, 1989) at the depth where the shells located (about $15 \mathrm{~cm}$ below the sediment surface).

Isotope fractionation of AVS: Seasonal variation of $\delta^{34} \mathrm{~S}$ values of AVS is distinguishable both inside and outside the shells (Fig. 6). And the difference of $\delta^{34} S$ of AVS between outside and inside of the shells is significant (minimum: $5.4 \%$; maximum: $19.8 \%$, average: $10.4 \%$ o). Almost constant $\delta^{34} \mathrm{~S}$ values for both sulfate and pyrite (end members of sulfur cycle) in the sediments outside and inside the shells indicate full recycling of sulfur compounds at the depth. AVS is an intermediate member of the cycle, and contains a large number types of sulfur compounds such as sulfite $\left(\mathrm{SO}_{3}{ }^{2-}\right)$, thiosulfate $\left(\mathrm{S}_{2} \mathrm{O}_{3}{ }^{2-}\right)$, inorganic $\mathrm{S}(-2)$ as bisulfide $\left(\mathrm{SH}^{-}\right)$and polysulfides, inorganic $\mathrm{S}(0)$ as polysulfides, inorganic polythionates, and $\mathrm{FeS}$ (Luther et al., 1986). Although thiols and organic disulfides are also intermediate members of the sulfur cycle, their reaction path is unclear. In anoxic marine sediments, bacterial activity that determines the components of AVS is affected significantly with coexisting substances (Luther et al., 1986; Aller and Rude, 1988).

The difference of AVS $\delta^{34} \mathrm{~S}$ values between inside and outside the shells is probably due to the difference of the composition of AVS components. The difference of the composition depends

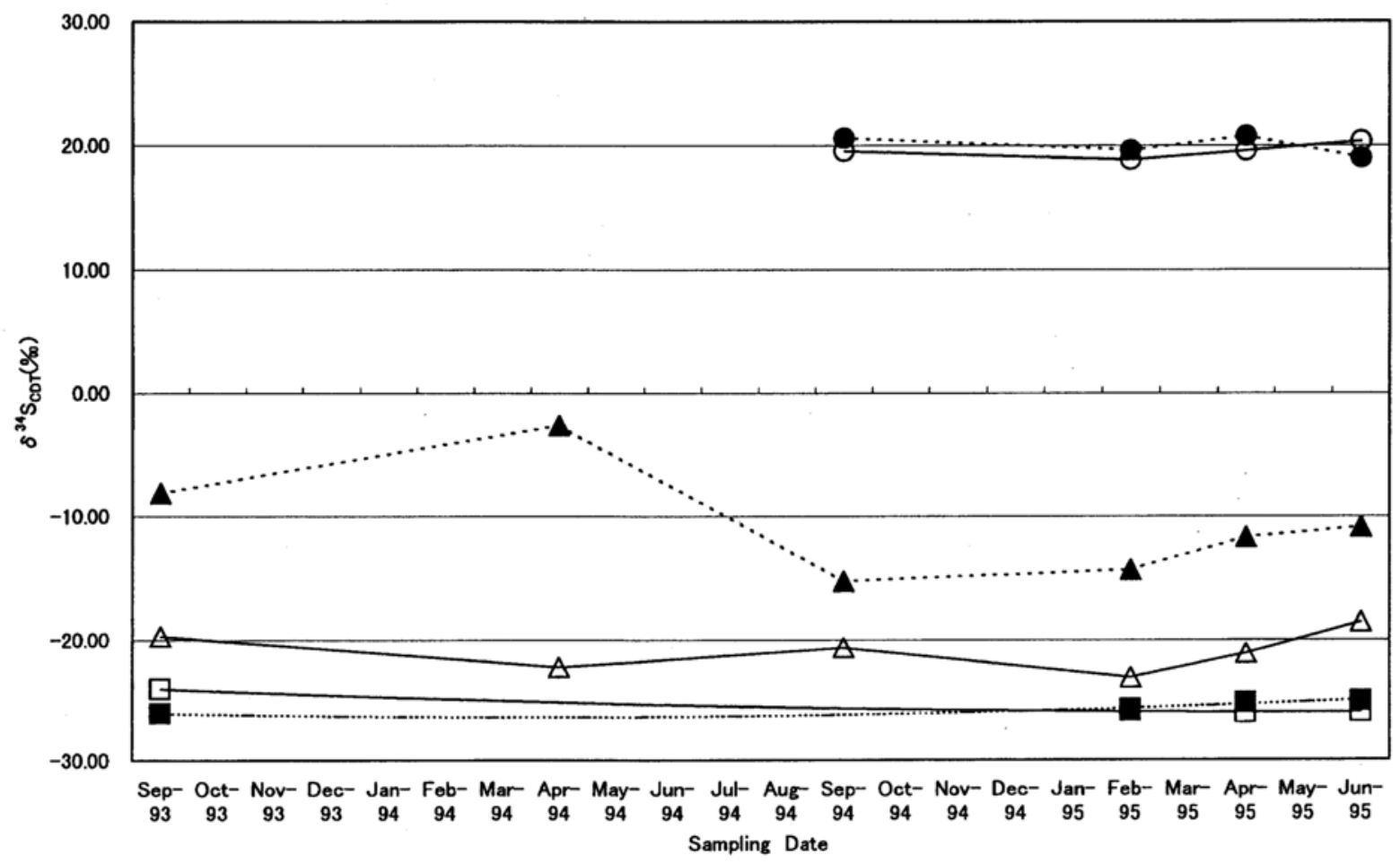

Fig. 6. Seasonal variations of $\delta^{34} S$ of sulfur compounds in the tidal flat sediments. $\bigcirc:$ Sulfate (exterior), ๑: Sulfate (interior), $\triangle$ : AVS (exterior), $\mathbf{\Delta}$ : AVS (interior), $\square:$ Pyrite (exterior), $\mathbf{\square}:$ Pyrite (interior). 
on the rate-determining steps in a series of transformation of the components. Luther and coworkers (1986) have suggested the importance of biogeochemical process for pyrite formation and its chemosynthetic recycling via thiols (such as glutathione) in salt marshes. In the chemosynthesis by organisms, one sulfur atom from pyrite is eventually converted to a thiol, and the other sulfur atom is completely oxidized to $\mathrm{SO}_{4}{ }^{2-}$ for its source of energy. This process does not necessar- ily require molecular oxygen to effect the oxidation, as is the case for chemical oxidation of pyrite. Such chemosynthetic oxidation of pyrite to $\mathrm{S}_{2} \mathrm{O}_{3}{ }^{2-}$ and $\mathrm{SO}_{4}{ }^{2-}$ by microbial catalysis can explain the apparent speed and ease of pyrite recycling in saltmarsh sediments. Aller and Rude (1988) have demonstrated complete oxidation of solid phase sulfides by manganese and bacteria in anoxic marine sediments. The net reaction is mediated by an unidentified group of bacteria, possibly

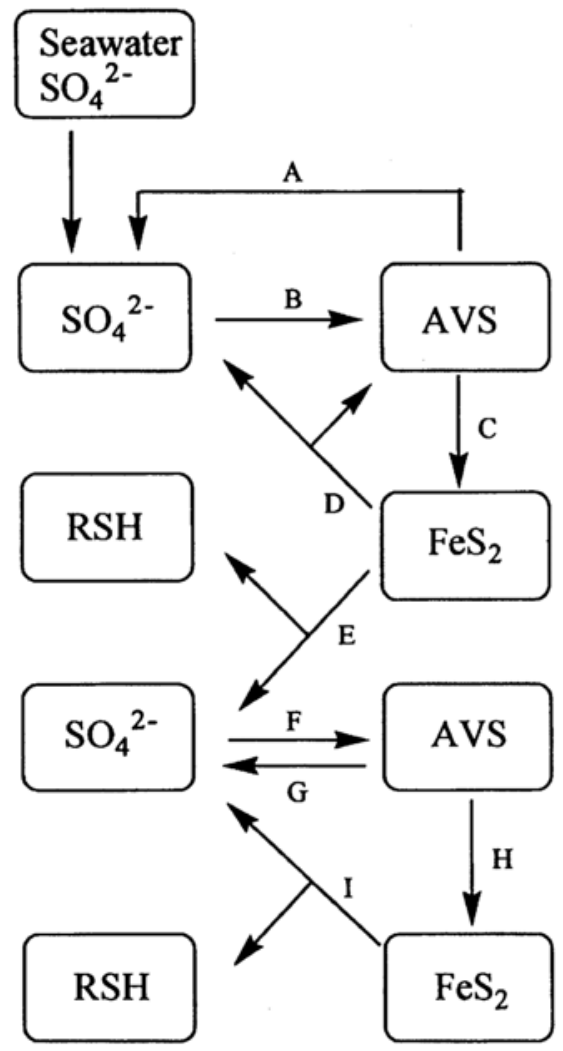

A: Bacterial and chemical aerobic $\left(\mathrm{O}_{2}\right)$ oxidation B \& F: Bacterial (SRB) reduction

C \& H: Abiotic reactions

$$
\begin{array}{ll}
\mathrm{SH} & \stackrel{\mathrm{Fe}^{2+}, \mathrm{S}_{8} / \mathrm{S}_{\mathrm{x}}{ }^{2-}}{\longrightarrow} \mathrm{FeS}_{2} \\
\mathrm{FeS}_{2} \stackrel{\mathrm{O}_{2}}{\longrightarrow} \mathrm{SO}_{4}{ }^{2-}+\mathrm{S}_{\mathrm{x}} \mathrm{O}_{6}{ }^{2-}+\mathrm{Fe}^{3+} \\
\mathrm{FeS}_{2} \stackrel{\text { Organic matter }}{\longrightarrow} \mathrm{RSH}+\mathrm{SO}_{4}{ }^{2-}+\mathrm{Fe}^{2+}
\end{array}
$$$$
\text { D: Abiotic oxidation }
$$

E \& I: Bacterial oxidation

G: Biologically (SB) mediated oxidation under anoxic condition

$$
4.5 \mathrm{MnO}_{2}+\mathrm{FeS}+7 \mathrm{CO}_{2}+4 \mathrm{H}_{2} \mathrm{O} \rightarrow 4.5 \mathrm{Mn}^{2+}+\mathrm{SO}_{4}{ }^{2-}+7 \mathrm{HCO}_{3}{ }^{-}+\mathrm{FeOOH}
$$

Fig. 7. Sulfur cycles in the tidal flat sediments. 
thiobacilli, which utilize Mn-S oxidation couple as basis for at least partial chemoautotrophic growth.

Figure 7 shows the possible overall sulfur cycling in the tidal-flat sediments. Loss of the organic sulfur compound (RSH) may occur by conversion to volatile forms, condensation to solid deposited phase, or metabolic use in chemosynthetic pathways (Luther et al., 1986). Although large isotope fractionation is observed during bacterial reduction processes (Rees, 1973), almost no isotope fractionation is expected for oxidation of sulfide to sulfate (Hallberg, 1985). Therefore, only reaction paths $\mathrm{B}$ and $\mathrm{F}$ contribute the isotope fractionation significantly.

At the layer very close to the surface $(0.5 \mathrm{~cm}$ depth), the cycle through paths A, B, C, and D is predominant (Figs. 5 and 7). The isotopically heavy sulfate remained after the path B is diluted with seawater sulfate. As the result of the cycle, isotopically light pyrite accumulates in the sediment. The secondary sulfate formed via the path E from the isotopically light pyrite is necessarily isotopically light. All of the sulfur compounds are recycled in the sediment below $0.5 \mathrm{~cm}$ from the surface. However, in the sediment between the depth of $0.5 \mathrm{~cm}$ and $7 \mathrm{~cm}$, the formation rate of pyrite exceeds the rate of destruction of pyrite to sulfate. Accordingly, isotopically heavy sulfate is concentrated in the remaining sulfate (Fig. 5). The loss of sulfate by reduction through the path $\mathrm{F}$ may be balanced with the formation of the sulfate via paths $G$ and $I$ below $7 \mathrm{~cm}$ from the sediment surface to keep the sulfate $\delta^{34} \mathrm{~S}$ values being constant (Fig. 5). The constant $\delta^{34} \mathrm{~S}$ values for sulfate and pyrite in the sediment samples inside and outside the shells indicate the preservation of the balance at the depth (ca. $15 \mathrm{~cm}$ ) through all seasons (Fig. 6).

No accumulation of each sulfur compound both outside and inside of the shells indicates that the average of the amount of the production and destruction of each compound through a year is in equilibrium. The tendency of seasonal variation of $\delta^{34} \mathrm{~S}$ values of the AVS is different between inside and outside of the shells (Fig. 6). Therefore, the remarkable difference of $\delta^{34} \mathrm{~S}$ values of AVS between inside and outside of the shells through all seasons is not interpreted by seasonal fluctuation of the contents of the sulfur compounds.

At the depth ca. $15 \mathrm{~cm}$ in our case, the composition of pyrite is much larger than other sulfur compounds (Fig. 4). Therefore, the $\delta^{34} \mathrm{~S}$ values of pyrite may not be affected by the change of $\delta^{34} \mathrm{~S}$ values of the AVS. The isotope fractionation through the path $\mathrm{F}$ causes positive shift of the sulfate $\delta^{34} \mathrm{~S}$. The transformation through the paths $\mathrm{G}$ or I yields negative shifts of the $\delta^{34} \mathrm{~S}$ values of the sulfate. In order to keep the sulfate $\delta^{34} \mathrm{~S}$ values constant, the positive and the negative shifts should counterbalance each other.

When remarkable isotope fractionation occurs only in the reaction by sulfur reduction bacteria (paths $\mathrm{B}$ and $\mathrm{F}$ in Fig. 7), the path $\mathrm{F}$ regulates the $\delta^{34} \mathrm{~S}$ values of the AVS inside and outside the shells. The number of SRB inside the shells is much larger than that of outside (Fig. 3). Therefore, the $\delta^{34} \mathrm{~S}$ values of AVS inside the shells should shift toward more negative values compare to that of outside, if the isotope-fractionation efficiency of SRB is the same for outside and inside. As the observed shift is opposite to that expected (Table 1 and Fig. 6), we need to assume the presence of different SRB having different isotope-fractionation efficiency for outside and inside of the shells. If so, the $\delta^{34} \mathrm{~S}$ of AVS will shift to negative values for both outside and inside the shells when the bacterial activity is high. The fluctuation of $\delta^{34} \mathrm{~S}$ values of the inside AVS is opposing to this prediction (Figs. 3 and 6).

In order to interpret the remarkable difference of $\delta^{34} \mathrm{~S}$ values of AVS between inside (average for all samples: $-10.45 \%$ ) and outside (average for all samples: $-20.90 \%$ o of the shells, we need to assume the isotope fractionation through the biologically mediated oxidation under anoxic conditions (path $\mathrm{G}$ in Fig. 7). If sulfur isotopes were fractionated through the path G, then isotopically heavy components will remain in the AVS to cause the shift of the $\delta^{34} \mathrm{~S}$ toward positive values. When the activity of bacteria mediating the path $G$ inside the shells is higher than that of 
outside, the $\delta^{34} \mathrm{~S}$ values of inside AVS will be more positive than outside. The aerobe in Fig. 3 contains chemosynthetic sulfur oxidation bacteria (SB) mediating path $\mathrm{G}$. The number of aerobe may reflect relative activity of the $\mathrm{SB}$, though the ratio of the SB to the whole aerobes is uncertain. The fact that the $\delta^{34} \mathrm{~S}$ of the inside AVS shifted to positive values when the number of aerobe was large (Figs. 3 and 6) shows well accordance with above presumptions. The decrease of the difference of AVS $\delta^{34} \mathrm{~S}$ values between outside and inside, when the number of aerobe decreases and the number of aerobe outside of the shells overcomes that of inside, is also indicated by the presumptions.

\section{Conclusions}

(1) Aerobic oxidation is the major driving force for sulfur recycling in sediments very close $(0.5$ $\mathrm{mm}$ depth from the sediment surface) to the sediment surface in the tidal flat. During this cycle, isotopically light sulfate is accumulated. This cycle continues until all free oxygen is consumed. Photosynthetic oxygen is the major source for the oxidation (Revsbech et al., 1980).

(2) Reduction of the sulfide by bacteria (SRB) is carried out accompanying the isotope fractionation among the sulfate, AVS, and pyrite at depths from $0.5 \mathrm{~cm}$ to $7 \mathrm{~cm}$ below the sediment surface. Accumulation of pyrite proceeds in this sedimental zone to make the shift of $\delta^{34} \mathrm{~S}$ values of the remaining sulfate toward positive direction.

(3) Full recycling of the sulfur compounds starts from $7 \mathrm{~cm}$ below the sediment surface. At the depth where the shells locate, the major sulfur compound is pyrite. The $\delta^{34} \mathrm{~S}$ values of sulfate and pyrite are almost constant for sediment samples from both outside and inside the shells. For the sulfate and pyrite, no difference of $\delta^{34} \mathrm{~S}$ values is observed between the samples from outside and inside the shells.

(4) The values of $\delta^{34} \mathrm{~S}$ of AVS are between that of sulfate and pyrite. The difference in $\delta^{34} \mathrm{~S}$ values of the AVS between the inside and outside sediments is quite significant. Seasonal variation of $\delta^{34} \mathrm{~S}$ values is observed for the AVS. The difference and variation of the AVS $\delta^{34} \mathrm{~S}$ values may be produced by unknown sulfur oxidizing bacteria (SB) which oxidize AVS into sulfate under anoxic conditions accompanied with significant sulfur-isotope fractionation.

Acknowledgments-We like to appreciate Drs. S. Kawaguchi, S. Shimoyama, M. Ohtsubo and H. Tsutsumi for many help in fieldwork, laboratories and discussion on analytical results. A part of this study was carried out under the Visiting Researcher's Program of the Institute for Study of the Earth's Interior, Okayama University. We thank Prof. M. Kusakabe and Ms. T. Nogi for their help and guidance during sulfur isotope analysis. Emeritus Prof. Tatsuro Matsumoto Scholarship and Takachiho Scholarship Fund supported this study.

\section{REFERENCES}

Alexander, M. (1965) Most-probable-number method for microbial populations. Methods of Soil Analysis Part2 2nd (Black, C. A., ed.), 1467-1472, Am. Soc. Agronomy, Wisconsin.

Aller, R. C. and Rude, P. D. (1988) Complete oxidation of solid phase sulfides by manganese and bacteria in anoxic marine sediments. Geochim. Cosmochim. Acta 52, 751-765.

Berner, R. A. (1984) Sedimentary pyrite formation: An update. Geochim. Cosmochim. Acta 48, 605-615.

Boulegue et al. (1982)

Hallberg, R. O. (1985) Computer simulation of sulfur isotope fractionation in a closed sulfuretum. Geomicrobiology J. 4, 131-152.

Howarth, R. W. (1979) Pyrite: Its rapid formation in a salt marsh and its importance in ecosystem metabolism. Science 203, 49.

Howarth, R. W. (1984) The ecological significance of sulfur in the energy dynamics of salt marsh and coastal marine sediments. Biogeochemistry 1, 5-27.

Ishikuri, S. (1992) MPN method. Experimental Methods of Soil Microbiology (Soc. Soil Microbio. Jpn., ed.), 45-52, Youkendo, Tokyo.

Kajiwara, Y. (1989) The potential contribution of biologically-controlled sulfur. Ann. Rep. Inst. Geosci. Univ. Tsukuba 15, 96-101.

Kaplan, I. R. and Rittenberg, S. C. (1964) Microbiological fractionation of sulfur isotopes. J. Gen. Microbio. 34, 195-212.

Kolthoff, I. M., Sandell, E. B., Meehan, E. J. and Bruckenstein, S. (1969) Quantitative analysis of sulfur as barium sulfate. Quantitative Chemical 
Analysis 4th ed., Collier-Macmillan Ltd., London.

Lord, C. J., III and Church, T. M. (1983) Geochim. Cosmochim. Acta 47, 1381.

Luther, G. W., III, Church, T. M., Scudlark, J. R. and Cosman, M. (1986) Inorganic and organic sulfur cycling in salt-marsh pore waters. Science 232, 746749.

Novitsky, J. A., Scott, I. R. and Keplay, P. E. (1981) Effects of iron, sulfur, and microbial activity on aerobic to anaerobic transitions in marine sediments. Geomicrobiol. J. 2, 211-223.

Ohmoto, H. and Felder, R. P. (1987) Bacterial activity in the warmer, sulphate-bearing, Archaean oceans. Nature 328, 244-246.

Ohtsubo, M. (1995) Formation of iron oxide in the surface zone of marine clay sediment and the geotechnical properties of clays. Trans. JSIDRE 63, 153-158.

Pooley, F. D. (1982) Bacteria accumulate silver during leaching of sulfide ore minerals. Nature 296, 642645.

Postgate, J. R. (1984) The Sulphate-Reducing Bacteria. 2nd ed., 208 pp, Cambridge Univ. Press.

Rees, C. E. (1973) A steady-state model for sulphur isotope fractionation in bacterial reduction processes. Geochim. Cosmochim. Acta 37, 1141-1162.

Revsbech, N. P., Sñensen, J. and Blackburn, T. H. (1980) Distribution of oxygen in marine sediments measured with microelectrodes. Limnol. Oceanogr. 25, 403-411.

Summons, R. E. (1993) Biogeochemical cycles; a review of fundamental aspects of organic matter formation, preservation, and composition. Organic Geochemistry (Engel, M. H. and Macko, S. A., eds.), 3-21, Plenum Press, New York.

Tsutsumi, H., Kikuchi, T., Higashi, T., Imasaki, K. and Miyazaki, M. (1991), Benthic faunal succession in a cove organically polluted by fish. Marine Pollution Bulletin 23, 223-238.

Yanagisawa, F. and Sakai, H. (1983) Thermal decomposition of barium sulfate-vanadium pentaoxide-silica glass mixtures for preparation of sulfur dioxide in sulfur isotope ratio measurements. Anal. Chem. 55, 985-987. 